\title{
Research on Rural Credit Capital Allocation Efficiency in Heilongjiang Province of China
}

\author{
----Based on the analysis of the DEA model
}

\author{
Lin Guo, Chen Guo \\ Department of economics Harbin University of Science and Technology, Harbin, China \\ g2bao@163.com, caihong7770@126.com
}

\begin{abstract}
To accelerate the development of the agriculture, we can not only increase the financial support but also pay attention to the allocation efficiency of the rural financial resources, so as to change the development of financial support from extensive to intensive. Therefore, it is necessary to make a scientific evaluation about the allocation efficiency of rural financial resource. Now, we use DEA model to make a vertical evaluation and analysis about the allocation efficiency of the rural credit funds each year in Heilongjiang province of China. The results show that in generally speaking, the allocation of rural funds in Heilongjiang province is effective, but not fully effective.
\end{abstract}

Index Terms - Agriculture, Research, Rural Credit Capital Allocation, DEA Model

\section{I . Foreword}

Whenever the agriculture is abundant, the foundation of one country is solid; so as the peasantry is rich, the country is prosperous. Also whenever the rural areas are peaceful, the society is stable. The new No.1 document from the CPC Central Committee which has focused on the questions about "agriculture, farmers and rural areas" for 9 years since 2004 was promulgated on February 1, 2012. It shows that Chinese government will press ahead with the building of the new socialist country, the development of rural economy and the reformation in rural areas, all which are important elements of building a harmonious socialist society. So China is making considerable effort to inject the cash into agriculture [1]. As Chinese largest province of agricultural, Heilongjiang province, is being more emphasis on agricultural credit support, so as to go ahead with the development of rural economy and the construction of new countryside.

\section{II . Overview of rural credit from the financial institutions in Heilongjiang province}

A . The proportion of the agricultural loans from the financial institutions is large and increases annually.

The statistics from the Statistical Division of the People's Bank of China in 2011 showed that the agricultural and rural loans in Heilongjiang province were RMB275.496 billion, which up 33.23 percent year-on-year and constituted 37.28 percent of the total loans and exceeded the national average by 14.18 percent by the end of 2010 . Among that, the rural loans were RMB199.842 billion, which accounted for 75.53 percent of the total agricultural and rural credit from the financial institutions. This fully indicates that as a large province of agriculture in China, rural financial service in Heilongjiang province is of larger proportion in its total financial service.

Besides, according to the statistics result of the statistic bureau in Heilongjiang province, in 2001, the agricultural loans in Heilongjiang province is RMB10 billion, while in 2010 it is 66.8 billion. It increased 5.68 times, and the average annual growth rate is 23.49 percent. In 2009, it grew fastest, which increased 97.33 percent. At the end of 2010, the agricultural loans in Heilongjiang province is 22.99 percent, which accounted for the short-term loans, it increased 19.13 percent compared with 3.86 percent in 2000 . It is 9.24 percent which accounted for the total loans, it increased 6.38 percent compared with 2.86 percent in 2000 . Generally speaking, the agricultural loan in Heilongjiang province increased fast in recent years, and the rural financial reform works well [2].

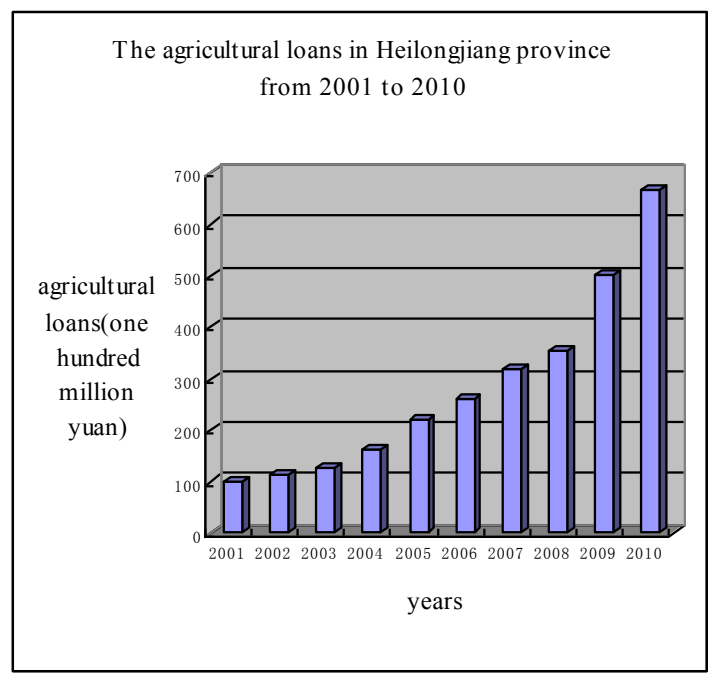

Fig. 1 The agricultural loans in Heilongjiang province from 2001 to 2010

B. The number of rural financial institutions and staff are increasing.

By the end of 2010, the policy banks, the branches of the Agricultural Development Bank of China in Heilongjiang province is 88 , and the number of staff is 2335 . The big commercial banks, the branches of the Industrial and Commercial Bank of China in Heilongiiang province is 593, 
and the number of staff is 16877. The branches of the Agricultural Bank of China in Heilongjiang province is 665, and the number of staff is 18314; the branches of the Bank of China in Heilongjiang province is 249 , and the number of staff is 7041; the branches of the China Construction Bank in Heilongjiang province is 436, and the number of staff is 11607.About rural cooperative financial institutions, the branches of the Rural Credit Cooperatives in Heilongjiang province is 1917, and the number of staff is 23037; the branches of the Rural Commercial bank in Heilongjiang province is 8 , and the number of staff is 108; the branches of the Rural Cooperative Bank in Heilongjiang province is 31 , and the number of staff is 283; the branches of the China Postal Savings Bank in Heilongjiang province is 15779 , and the number of staff is 13500; besides that, there has established 10 Village Banks and 4 Rural Credit Union Funds so far.

\section{The construction of credit reporting system of financial institutions is speeding up.}

By the end of 2010, the agricultural financial institutions in Heilongjiang province has set up the credit file for 3.5 million farmers, of which 1.47 million farmers input file information management and electronic credit rating system. 720000 farmers obtain loans support valued 22.2 billion Yuan. At the same time, it strengthened the financial institutions credit rating work instruction, and tried to combine the internal and external ratings [3].

According to the statistics above, the agricultural support of financial institutions in Heilongjiang province has a steady increase. Therefore, it is necessary to speed up the development of the agriculture, we can not only increase the financial support but also pay attention to the rural financial resources allocation efficiency, so as to make financial support change from extensive to intensive development. Therefore, it is necessary to make a scientific evaluation of the rural financial resources allocation efficiency. On this basis, we can clarify the factors influencing the efficiency of rural financial resource allocation, and then provide useful lessons for the improvement of rural financial environment. Based on the above thinking, this study selected the DEA model to evaluate and analyze the rural financial efficiency of resource allocation in Heilongjiang Province from 2001 to 2009.

\section{Analysis of rural credit found alloncation efficiency Heilongjiang Province based on DEA Model}

\section{A . The description of DEA model.}

Data Envelopment Analysis (DEA) is a non-parametric technique for evaluating the performance of many activities. DEA evaluates the relative efficiency of a set of homogenous decision making units (DMUs) by using a ratio of the weighted sum of outputs to the weighted sum of inputs. Specifically, it determines a set of weights so that the efficiency of a target DMU relative to the other DMUs is maximized.
Various theoretical extensions have been developed. Based on the original CCR model: Bankeretal (1984) developed a variable returns-to-scale variation; the multiplicative model was developed by Charnesetal (1982), in which the data are transformed educing a logarithmic structure; Charnesetal (1985) developed the additive variation, in which the objective function contains slack variables alone. Seiford and Thrall (1990) provided a useful discussion and comparison of all the basic models available to data in DEA.

DEA has been used in several contexts including education systems, healthcare units, agricultural production, and military logistics.Amade(1994), Charnesetal(1994), Cooperetal(1994).

The frequently used DEA models are the CCR model, named after Charnes,Cooper, and Rhodes, and the BCC model, named after Banker, Charnes, and Cooper.

In this paper, we use the constant returns to scale, inputoriented CCR model to analyze the technical efficiency of capital allocation of agricultural credit in Heilongjiang Province from 2001 to 2009 . So we describes the CCR model only.

The model assumes constant returns to scale (CRS) and take each year as a decision-making unit, to make a longitudinal evaluation and analysis of the efficiency of each year in Heilongjiang rural credit.

Assume that there is $t$ years, of each year there are $p$ types of inputs and $q$ types of outputs. $X_{i j}$ represents The total amount of the $i$ credit resources input of $D M U_{j}$ (in the $j$ year), while $Y_{r j}$ represents the total amount of the $r$ output in the $j$ year.. Then $D M U_{j}$ (in the $j$ year) the input of the credit resource is $X_{j}=\left(x_{1 j}, x_{2 j}, \cdots x_{p j}\right)^{T}$ the output is $Y_{j}=\left(y_{1 j}, y_{2 j}, \cdots y_{q j}\right)^{T}$. Let $v_{i}$ be the weight of the input of the $i$ credit resource, while $u_{r}$ be the weight of the $r$ output. Then the weight vector of the input vector $X$ is $V=\left(v_{1}, v_{2}, \cdots v_{p}\right)$; while the weight vector of the output vector $Y$ is $U=\left(u_{1}, u_{2}, \cdots u_{q}\right)$.

The efficiency index of the $j$ year is

$$
h_{j}=\frac{U^{T} Y_{j}}{V^{T} X_{J}}, j=1,2,3, \cdots t
$$

Among that, $X_{j}$ is the $p$ dimensional input column vector of the credit resources of $D M U_{j}$ (in the $j$ year), while $Y_{j}$ is the $q$ dimensional output column vector of $D M U_{j}$ (in the $j$ year). $V$ is the $p \times 1$-order weight coefficient matrix of the input elements, while $U$ is the $q \times 1$-order weight coefficient matrix of the output elements.

Choose the appropriate non-negative weight coefficient matrix $U$ and $V$, making that

$$
h_{j} \leq 1, j=1,2, \cdots, t
$$


Efficiency index $h_{j}$ means the ratio of output to input in the case of the weight coefficient matrix are $U$ and $V$, and the input and output are $V^{T} X_{j}$ and $U^{T} Y_{J}$.

Make the rural credit efficiency of $D M U_{j}$ (in the $j$ year) as the objective function, and make the efficiency index of all the provinces as the constraint conditions. If one of the $D M U_{\text {中 }}$ efficiency is the highest, and the efficiency evaluation index is

$$
h_{\text {中 }}=\frac{U^{T} Y_{\text {中 }}}{V^{T} Y_{\text {中 }}}
$$

Then, the efficiency index of other $D M U$ for the standard of evaluation with $D M U_{\text {中 }}$ is

$$
h_{j}=\frac{U^{T} Y_{j}}{V^{T} X_{J}} \leq 1(j=1,2,3, \ldots t)
$$

Among that, $X_{j}$ is the $p$ dimensional input column vector of the credit resources of $D M U_{j}$ (in the $j$ year), while $Y_{j}$ is the $q$ dimensional output column vector of $D M U_{j}$ (in the $j$ year). $V$ is the $p \times 1$-order weight coefficient matrix of the input elements, while $U$ is the $q \times 1$-order weight coefficient matrix of the output elements. According to formula 3.3 and 3.4 we can deduce the input-oriented CCR model:

$$
\begin{aligned}
& \max h_{j u}=\frac{U^{T} Y_{j u}}{V^{T} X_{j u}} \\
& \text { s.t } \frac{U^{T} Y_{j u}}{V^{T} X_{j u}} \leq 1, U \geq 0, V \geq 0, j=1,2,3, \cdots t
\end{aligned}
$$

Use the Charnes-cooper conversion, we can transform the non-linear CCR model 3.5 into the equivalent linear model:

$$
\begin{aligned}
& \min \left[\theta-\varepsilon\left(\hat{e}^{T} S^{-}+e^{T} S^{+}\right)\right] \\
& \text {st } \sum_{j=1}^{t} \lambda_{j} x_{i j}+S^{-}=\theta x_{*} \\
& \sum_{j=1}^{t} \lambda_{j} x_{i j}-S^{+}=\theta y_{*} \\
& \sum_{j=1}^{t} \lambda_{j}^{*}=1
\end{aligned}
$$$$
S^{-} \geq 0, S^{+} \geq 0, \lambda_{j} \geq 0, j=1,2,3, \cdots t
$$

\section{Among}

that: $\quad \hat{e}^{T}=(1, \cdots, 1) \in R^{m} ; e^{T}=(1, \cdots, 1) \in R^{n} ; S^{-}=\left(s_{j 1}^{-}, s_{j 2}^{-}, \cdots, s_{j m}^{-}\right)^{T}$

represents the input which can be reduced compared with the optimal value; $S^{+}=\left(s_{j 1}^{+}, s_{j 2}^{+}, \cdots s_{j s}^{+}\right)^{T}$ represents the output which can be increased compared with the optimal value; $X_{*}$ and $Y_{*}$ are the input and output column vector of the DMU under evaluation; $\theta$ is the relative efficiency; $\varepsilon$ is NonArchimedean infinitesimal. Let $\theta^{*} 、 S^{+^{*}} 、 S^{-*} 、 \lambda^{*}$ be the optimal solutions of the Model 3.6, if $\theta^{*}=1$ and $S^{+^{*}}=0$ or $S^{-^{*}}=0$, we can say that the rural credit is DEA effective in the $j$ year; meaning that has the technical efficiency. If $\theta^{*}<1$, we say that the rural credit is DEA non-effective, meaning that the technical efficiency is not the best at this time.

\section{$B$. Index selection and data sources.}

This paper aims to study the utilization efficiency of the rural credit funds in Heilongjiang province in recent years. Considering that part of the data of 2010 can not be collected, we selected nine years from 2001 to 2009 as the decisionmaking units. The sources of rural credit funds can generally regard the system, organizations, financial institutions, human and other factors[4]. Considering the availability of the data, this paper selects the agricultural loans balances and the township enterprise loans balances from the financial institutions as the input indicators; while selects the agricultural GDP, the added value of township enterprises and the household of rural residents as the output indicators. The specific conditions of the select indicators are showed in Table I.

TABLE I The evaluation index of the rural credit funds efficiency in Heilongjiang province

\begin{tabular}{|c|l|}
\hline category & \multicolumn{1}{|c|}{ indicators } \\
\hline \multirow{3}{*}{ input } & $\begin{array}{l}\text { agricultural loans balances from the financial institutions } \\
\text { (one hundred million Yuan) }\end{array}$ \\
\cline { 2 - 2 } & $\begin{array}{l}\text { township enterprise loans balances from the financial } \\
\text { institutions (one hundred million Yuan) }\end{array}$ \\
\hline \multirow{3}{*}{ output } & $\begin{array}{l}\text { agricultural GDP (one hundred million Yuan) } \\
\text { (one hundred million Yuan) }\end{array}$ \\
\cline { 2 - 2 } & \begin{tabular}{l} 
household of rural residents (one hundred million Yuan) \\
\hline
\end{tabular} \\
\hline
\end{tabular}

C. DEA evaluation and analysis of the allocation efficiency of the agricultural credit in Heilongjiang province.

Based on the aforementioned input-oriented CCR model, taking the data of indicators selected into the DEA software DEAP2.1, we can get the technical efficiency of capital allocation of agricultural credit in Heilongjiang province from 2001 to 2009, using "VRS" expressed. This efficiency index focus on the efficiency of the relevant system which operation 
in the agricultural credit capital allocation [5]. The results are shown in Table II.

TABLE II The technology efficiency of the agricultural credit capital allocation in Heilongjiang province from 2001 to 2009(VRS)

\begin{tabular}{|l|l|l|l|l|l|l|}
\hline 2001 & 2002 & 2003 & 2004 & 2005 & 2006 & 2007 \\
\hline 1.000 & 0.997 & 1.000 & 0.991 & 0.972 & 1.000 & 0.880 \\
\hline 2008 & 2009 & \multicolumn{5}{|l}{} \\
\cline { 1 - 2 } 1.000 & 1.000 & \multicolumn{1}{|l}{} &
\end{tabular}

Postscript: It is effective when the value of VRS is 1, and the smaller the value the worse the efficiency.

\section{IV . Conclusions}

The average technical efficiency of the rural credit funds in Heilongjiang province from 2001 to 2009 is 0.982 , which demonstrates that in generally speaking, the rural funds credit allocation in Heilongjiang province is effective, but not fully effective. As the technical efficiency reflects the efficiency of capital allocation of agricultural credit funds related system operation, so the system constructions of the agricultural credit funds allocation are still imperfect.

On the condition that the average technical efficiency is less than 1 , the technical efficiency of rural credit funds in Heilongjiang province in the year 2001, 2003, 2006, 2008, 2009 is 1 , which means that the rural credit capital allocation is fully effective in these years. This can be explained by the comprehensive analysis about China's rural financial policy and situation and the rural financial construction in Heilongjiang province in the past few years. The year 2001 is the first year of the national "Eleventh Five-Year", and the support for agriculture is increasing in this year. In 2006, the agricultural tax was rescinded. At the same time, the Heilongjiang rural credit cooperatives reform from 2005 is working, which makes the financial institutions prefer to invest in countryside rather than in city [6]. The initiative of the farmers also makes the fouds get a good application. Those all realize the optimal allocation efficiency. In 2008, People's Bank of China and Banking Regulatory Commission issued the "opinions on accelerating the innovation of rural financial products and services" jointly, and some counties (cities) in Heilongjiang province were chosen as the first pilot. From then on, the rural credit allocation efficiency in Heilongjiang province is promoted effectively [7].
In conclusion, the fluctuations in the efficiency of rural credit in Heilongjiang province is closely related to the outside world financial ecological environment, national and regional policies on rural finance (such as the abolition of agricultural tax). When these factors can effectively promote the development of rural economy, the efficiency of the rural credit will rise; or it will down [8].

At the same time, the construction of the main institutions in the rural financial system under the action of the construction of national and regional policy, as well as use of funds of township enterprises and farmers also have a significant impact on the efficiency of the allocation of rural credit funds [9]. When the rural financial institutions system runs well and township enterprises and farmers use their funds reasonable, the efficiency of the rural credit will rise; or it will down.

\section{Acknowledgments}

This work was supported by the Philosophy social sciences projects in Heilongjiang Province under Grant Nos. $12 \mathrm{C} 030$.

\section{References}

[1] Leiling Wang, Jianzhao Luo, "Whether the rural informal finance will inhibit economic growth or not? - Shaanxi for example", Economic Survey, Vol.5, No.4, pp.156 160, 2011.

[2] Zhujun Ding "Rural financial supply model of foreign enlighten China", Economic world, Vol .22, No.34, pp.76 79, 2011.

[3] Lin Zhou, "Defect analysis of formal rural financial supply", Financial economy, Vol.2, No.4, pp.43 44, 2011.

[4] Anan Zheng, "The effective supply of the rural finance in Heilongjiang province", Northeast Agricultural University, Vol.6, No.5, pp.8, 2009.

[5] Wenxiang Lu, "Supply analysis of rural financial service system", Modern business industry, Vol.19, No.12, pp.21 23, 2011.

[6] Min Chen, Jing Sun, "Formal financial development of the rural areas in Heilongjiang province", Harbin University of Commerce (Social Science Edition), Vol.2, No. 427 30, 2010.

[7] Min Zhao, "Building rural formal financial organization system from the viewpoints of the demand", The Party School of, Vol.4, No. 13, pp. 53 55, 2006.

[8] Juan Li, Zuting Zheng, "Study on Evaluation of Technical Innovation Capacity of High-tech Industry with Uncertain Linguistic Information", AISS, Vol. 4, No. 4, pp. $230 \sim 236,2012$

[9] Xuehua Liu, "Model for Evaluating the Risk Management of Trade Enterprise with Interval Intuitionistic Trapezoidal Fuzzy Information", AISS, Vol. 4, No. 4, pp. $11 \sim 17,2012$ 